\title{
Large scale synthesis and characterization of cadmium sulfide nanoparticles by simple chemical route
}

\author{
A. S. Garde \\ Department of Physics, SPH Arts, Science and Commerce College Nampur Dist. Nasik 423 204, \\ Savitribai Phule University Pune, Maharashtra, India \\ arungarde@yahoo.co.in
}

DOI 10.17586/2220-8054-2020-11-4-444-452

\begin{abstract}
Large scale cadmium sulfide nanoparticles were synthesized by simple chemical route. The microstructure of cadmium sulfide nanoparticles was characterized by X-ray diffraction pattern (XRD) FESEM, FTIR and UV-visible spectroscopy. The XRD results showed that there was a transformation from cubic to hexagonal crystalline phase. The $\mathrm{W}-\mathrm{H}$ plots show the size and nature of the strain incorporated in peak broadening of $\mathrm{X}$-ray diffraction peaks. Some of the observed peak broadening can be attributed to crystallite size and microstrain effects, dislocation density, hkldependent peak broadening and peak shifts are clearly associated with stacking faults. The refractive index of the CdS nanoparticles was estimated to 2.22. The optical band gap of the synthesized CdS nanoparticles was calculated by Tauc relation and found to be 3.45 eV. The dependence of the blue shift and optical band gap on the quantum size effect was confirmed by UV-Visible spectroscopy. FTIR study confirmedthat the -C-O and $-\mathrm{OH}$ groups of thioglycerol can readily bind with $\mathrm{CdS}$ nanoparticles.
\end{abstract}

Keywords: $\mathrm{CdCl}_{2}$, material behavior-XRD, microstructure, FESEM, UV-visible spectroscopy, FT-IR.

Received: 31 March 2020

Revised: 13 May 2020

\section{Introduction}

Nanotechnology is the most promising technology that can be applied in almost all spheres of life, ranging from pharmaceuticals, defense, electronics, transportation, heat transfer, as well as sports and aesthetics. Cadmium sulfide is one of the most studied materials, with a band gap of $2.43 \mathrm{eV}$ and also these are ideal quantum confined semiconductors due to its optical and electronic properties [1]. For fabrication of p-n junction solar cells, CdS (n-type material) along with p-type materials like copper indium gallium diselenide (CIGS), copper zinc tin sulfide (CZTS), gallium arsenide (GaAs), indium phosphide (InP), cadmium telluride (CdTe) etc. have been used [2,3]. Due to wide band gaps, CdS is used as window material carriers, which improve solar cell efficiency [4]. Also, it is primarily used in solar cell and a variety of electronic devices. The photoconductive and electroluminescent properties of cadmium sulfide have been applied in manufacturing a variety of consumer goods. $\mathrm{CdS}$ is an attractive visible-light photocatalyst because of its desired band gap, oxidation and reduction potential. CdS may also act as important sensitizers, which can sensitize the wide band gap semiconductor and this improves the photocatalytic activity and stability of the photocatalyst [5]. II-VI semiconductor nanoparticles are currently of great interest for their practical applications, such as zero dimensional quantum confined materials in light emitting diodes [6], photo detectors [7], FET [8], photoluminescence [9], infrared photo detector [10], and environmental and biological sensors [11]. There are many ways to prepare semiconductor nanoparticles, including some physical methods, such as low pressure, gas evaporation method, chemical methods such as settling, hydrolysis, hydrothermal, sol-gel, electric spark, sluggish precipitation [12]. Cadmium sulfide nanoparticles is an extremely insoluble and stable, so sulfide producing microorganisms can be used at contamination site to detoxify the heavy metals [13]. Apart from chemical synthesis,another well-known route for $\mathrm{CdS}$ nanoparticle synthesis is the biosynthesis of CdS nanoparticles, which can be carried out by using microorganisms, fungi and plants. In that synthesis, the microbes involved should isolate the $\mathrm{Cd}^{+2}$ ions from their metal solution and accumulate them in a reduced state by different enzymes and metabolites secreted by their activity [13]. Various morphologies of CdS nanocrystals have been previously reported, such as flakes [14], spheres [15], dendrites [16] nanowires nanorods [17] and other structures were dominant.

The aim of present work is to prepare large scale cadmium sulfide nanoparticles using a simple chemical route and to investigate their microstructure and optical properties. 


\section{Experimental}

\subsection{Chemicals used}

Cadmium (II) Chloride ( $\mathrm{CdCl}_{2}$ AR $99 \%$ Pure), Sodium sulfide flakes $\mathrm{Na}_{2} \mathrm{~S}$ (99\% pure) from Vishal and 1-Thioglycerol $\left(\mathrm{HSCH}_{2} \mathrm{CH}_{2} \mathrm{OH}\right.$ ) from Loba Chem. of analytical grade, were purchased and used without further chemical treatment and purification. $\mathrm{Na}_{2} \mathrm{~S}$ and $\mathrm{HSCH}_{2} \mathrm{CH}_{2} \mathrm{OH}$ were used as reducing agent. De-ionized water was prepared in our laboratory and it was used as solvent throughout the preparation.

\subsection{Synthesis of cadmium sulfide nanoparticles}

A $25 \mathrm{ml}$ of 1 molar Cadmium (II) Chloride $\left(\mathrm{CdCl}_{2}\right.$, AR $99 \%$ pure) solutions was prepared by dissolving in de-ionized water. Solutions of $2.0 \mathrm{M} \mathrm{Na}_{2} \mathrm{~S}$ were prepared in $50 \mathrm{ml}$ de-ionized water. A $25 \mathrm{ml}$ of $\mathrm{CdCl}_{2}$ solution were heated continuously at $90^{\circ} \mathrm{C}$ temperature under vigorous stirring on magnetic stirrer with heater (electrical/mechanic). 2.0 molar concentration of sodium sulfide $\left(\mathrm{Na}_{2} \mathrm{~S}\right)$ solution was added drop wise to formation of stoichiometry solution. Then, 1-thioglycerol was added to the reaction medium. Thioglycerol $\left(\mathrm{HSCH}_{2} \mathrm{CH}_{2} \mathrm{OH}\right)$ was used as a capping agent, leading to the formation of colloidally-stable CdS nanoparticles with controlled aspect ratios. Capping agent is widely used for preparation of nanoparticles because the hydroxyl group confers solubility in water and lowers the volatility. The heating and mixing continued till the color changed to gradually turned from light to dark yellow. The yellow product was collected by centrifugation at $5000 \mathrm{rpm}$ for 20 minutes and washed three times with ethanol and double distilled water. Dark yellow color indicated the formation of fine nanoscale cadmium sulfide particles from thioglycerol-assisted reduction [18]. The obtained product was dried under IR lamp for few hours and sintered at $200{ }^{\circ} \mathrm{C}$ in air for 1 hour. Various optimization studies were performed to investigate the size and shapes of $\mathrm{CdS}$ nanoparticles. The whole process was completed within 5-6 hours. Molar concentration ratio of solution was increased then large scale of nanoparticles was obtained. The chemical reaction is as follows:

$$
\mathrm{CdCl}_{2}+\mathrm{Na}_{2} \mathrm{~S} \rightarrow \mathrm{CdS}+2 \mathrm{NaCl}
$$

\subsection{Material characterization}

The cadmium sulfide nanoparticles were characterized by X-ray diffraction technique [Bruker D-8 model, DMAX-

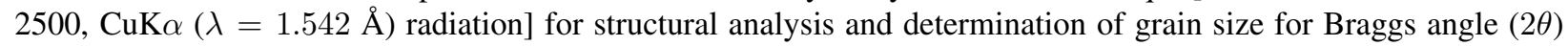
from 20 to 80 degree. The crystallites size was determined by using Debye Scherrer formula [19]:

$$
D=\frac{0.9 \lambda}{\beta \cos \theta} \text {. }
$$

The dislocation density $(\delta)$ was calculated from equation:

$$
\delta=\frac{n}{D^{2}},
$$

where $n$ is a factor and $D$ is the crystallite size [20].

RMS microstrain (e) was determined using a Williamson and Hall plot. The slope of the plot of $\frac{\beta \cos \theta}{\lambda}$ versus $\frac{2 \sin \theta}{\lambda}$ gives the value of the RMS microstrain. The stacking fault probability was calculated from the peak shift using the following equation:

$$
\therefore \alpha=\frac{2 \pi^{2} \Delta(2 \theta)}{45 \sqrt{3} \tan \theta(h k l)} .
$$

The calculated values of lattice parameters for cubic crystal structure were estimated by using Nelson-Riley plots [20]:

$$
\therefore f(\theta)=\frac{1}{2}\left[\left(\frac{\cos ^{2} \theta}{\sin \theta}\right)+\left(\frac{\cos ^{2} \theta}{\theta}\right)\right] \text {. }
$$

The UV-visible optical absorption spectra were measured in the $200-400 \mathrm{~nm}$ range. A record spectrophotometer (JASCO UV-VIS-NIR Model No.V-670) was used for these optical measurements. The infrared spectrum was measured at room temperature in the wave number range $400-4000 \mathrm{~cm}^{-1}$ by a Fourier Transform infrared spectrophotometer (FT/IR-6100 Shimadzu). For that analysis, the samples were pulverized into fine powder and then mixed with $\mathrm{KBr}$ powder in a weight ratio of $(1: 100)$. 


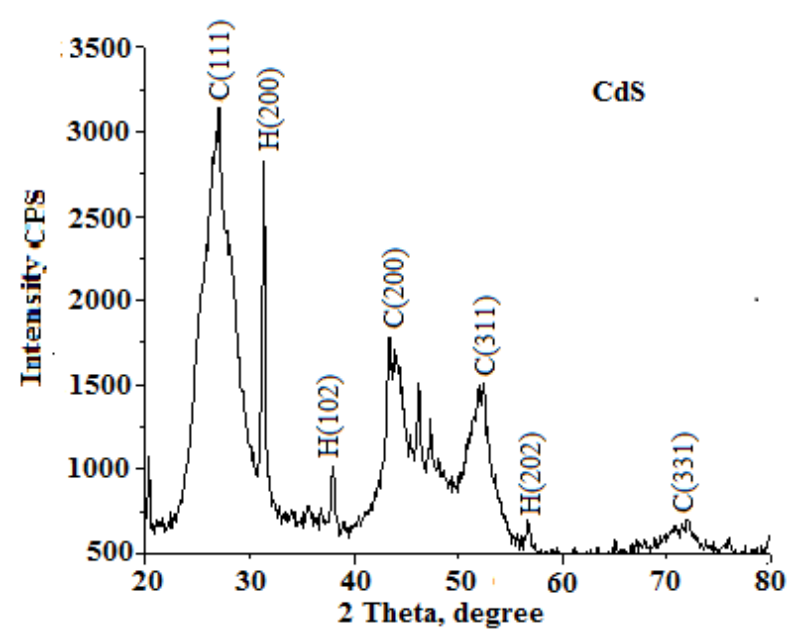

FIG. 1. XRD pattern of CdS nanoparticles sintered at $200{ }^{\circ} \mathrm{C}$

\section{Results and discussion}

\subsection{X-Ray diffraction (XRD)}

Figure 1 shows an XRD pattern of $\mathrm{CdS}$ nanoparticles sintered at $200^{\circ} \mathrm{C}$ plotted in the range $20-80^{\circ}$.

In this pattern, the significantly broader hump and less intense peaks in the XRD pattern that were observed are indicative of the small size for the CdS nanoparticles and they are in agreement with small FWHM peaks. This also confirms the stoichiometric nature of nanoparticles. The line broadening of the peak was used to calculate the average crystallite size of the CdS nanoparticles using the Scherrer formula [19]. The XRD pattern shows number of peaks of CdS nanoparticles phases, indicating a face centered cubic structure for the cadmium sulfide [JCPDS Card No. 89-0440]. It contains a minorwurtzite hexagonal phase of CdS [JCPDS Card No. 80-006]. CdS phase was most often appear in synthesized colloidal CdS particles, but the macro scale phase of CdS is normally with the hexagonal structure [21]. I have been obtained cubic phase as well as minor hexagonal phase in the present preparation of CdS nanoparticles. The observed peaks show the presence of cadmium sulfide phases which match well with reported JCPDS data confirming pure CdS phase structure. The XRD pattern of the CdS nanoparticles exhibits prominent, broad peaks at $2 \theta$ values of $26.81,31.32,37.94,43.96,51.28,58.89$ and 71.22 which could be indexed to scattering

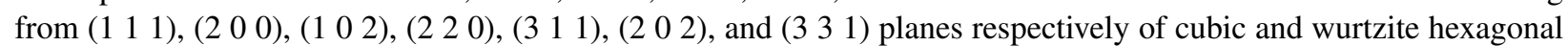
structure of CdS [22]. The higher peak intensities of the XRD pattern are due to the better crystallinity and larger grain size and can be attributed to particle agglomeration. It has been observed that (111) reflections are of maximum intensity, which indicates that $\mathrm{CdS}$ nanoparticles have a preferred orientation in the (111) plane. One shoulder sharp intense peak at $2 \theta$ value of 31.32 was identified scattering from (200) plane (JCPDS-010705-0581). The measured peaks are in good agreement with other studies.

It is evident from the following (Table 1) that the data obtained are well matched with the standard values of CdS crystal [23].

3.1.1. Nelson-Riley plots. The spacing between diffracting planes $(d)$ of synthesized CdS nanoparticles was calculated from the Bragg equation

$$
n \lambda=2 d \sin \theta
$$

Lattice parameter of the cubic $(a=b=c)$ and hexagonal $(a=b \neq c)$ crystal is calculated using the formula,

$$
\frac{1}{d^{2}}=\frac{h^{2}}{a^{2}}+\frac{k^{2}}{a^{2}}+\frac{l^{2}}{a^{2}} \quad \text { and } \quad \frac{1}{d^{2}}=\frac{h^{2}}{a^{2}}+\frac{k^{2}}{a^{2}}+\frac{l^{2}}{c^{2}},
$$

where, $d$ is the atomic lattice spacing, $h, k$ and $l$ are miller indices; $a$ is the lattice parameter of the crystal. Crystal lattice parameter and cell volume of cubic and hexagonal structure of CdS was observed from XRD pattern. It was found to be $5.8168 \& 5.1506 \AA$ and 196.81 and $108.89 \AA^{3}$ respectively. The calculated values of the lattice parameters for cubic crystal structure were estimated by using Nelson-Riley plots [24].

Figure 2 shows the Nelson-Riley curve was plotted of error function by the extrapolation $f(\theta)$ against lattice parameter (a) for cubic and hexagonal (c) crystal were obtained. By using eq. (4), the extrapolation $f(\theta)$ was calculated. The corrected values of lattice parameter were estimated for cubic (a) and hexagonal (c) crystal is 5.760 and $5.198 \AA$. 
TABLE 1. Observed and calculated diffraction angles, d-spacing, crystallite size with (hkl) planes cadmium sulfide nanoparticles

\begin{tabular}{ccccccc}
\hline $\begin{array}{c}\text { Observed } \\
\text { diffracting } \\
\text { angle }(2 \theta) \\
\text { degrees }\end{array}$ & $\begin{array}{c}\text { Calculated } \\
\text { diffracting } \\
\text { angle }(2 \theta) \\
\text { degrees }\end{array}$ & $\begin{array}{c}\text { Observed } \\
\text { d-Spacing } \\
\text { in } \AA\end{array}$ & $\begin{array}{c}\text { Calculated } \\
\text { d-Spacing } \\
\text { in } \AA\end{array}$ & $\begin{array}{c}\text { hkl } \\
\text { (Planes) }\end{array}$ & $\begin{array}{c}\text { Crystallite } \\
\text { size } \\
\text { in nm }\end{array}$ & $\begin{array}{c}\text { Lattice } \\
\text { parameter } \\
\text { of the crystal (a) }\end{array}$ \\
\hline \hline 26.81 & 28.22 & 3.3214 & 3.3257 & $\mathrm{C}(111)$ & 38.55 & 5.7603 \\
31.32 & 32.51 & 2.8644 & 2.8562 & $\mathrm{H}(200)$ & 43.92 & 5.4817 \\
37.94 & 36.62 & 2.3660 & 2.3718 & $\mathrm{H}(102)$ & 50.95 & 3.9655 \\
43.96 & 44.22 & 2.0598 & 2.0595 & $\mathrm{C}(220)$ & 51.63 & 5.8251 \\
51.28 & 52.10 & 1.7336 & 1.7817 & $\mathrm{C}(311)$ & 46.60 & 5.9092 \\
58.89 & 58.27 & 1.5499 & 1.5684 & $\mathrm{H}(202)$ & 48.56 & 4.7722 \\
71.22 & 72.71 & 1.3187 & 1.3244 & $\mathrm{C}(331)$ & 41.33 & 5.7729 \\
\hline
\end{tabular}

The lattice parameters corresponding to each peak reflections were plotted against a Nelson-Riley function and the precise lattice parameter were taken from the intercept out of linear fit. The Nelson-Riley curve showed a high quality of crystallization of CdS nanoparticles. They are in good agreement with the results of JCPDS data.
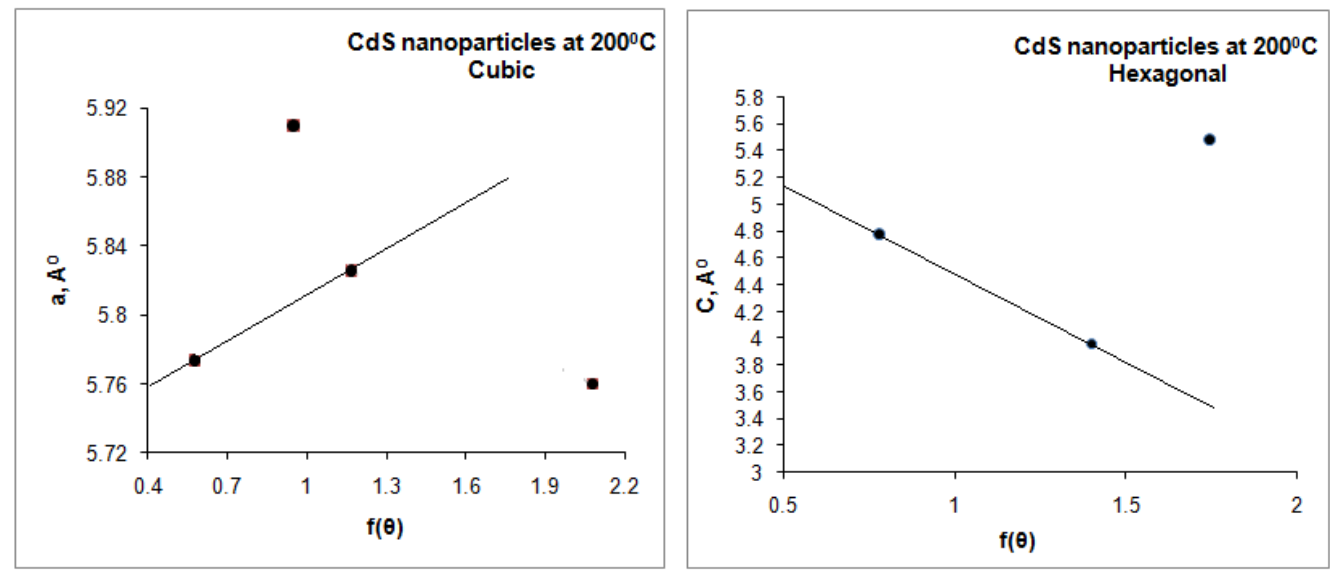

FIG. 2. Nelson-Riley plot for lattice parameters for CdS nanoparticles synthesized by simple chemical route

When the temperature is increased, crystallinity tends to increase with decrease in lattice constant $(a=6.29,5.88$, 5.87 and $5.85 \AA$ ) and increase in the particle size [25]. Particle growth usually occurs via the mechanism of Ostwald ripening. Larger particles grow on account of dissolution of smaller ones. As a result, the particle size increases continuously during the growth as temperature increases [26].

3.1.2. Dislocation density. The dislocation density is the length of dislocation lines per unit volume of the crystal this means crystallographic defect with in a structure of crystal which contains an abrupt change in the arrangement of atoms. In the literature, dislocation strongly influences many of the properties of materials, such as slip, surfaces, interfaces, irradiation, pining, climb etc.

The X-ray diffraction pattern of CdS analysis has been used to determine the dislocation density. Accordingly, it was observed that the crystallite size of the $\mathrm{CdS}$ nanoparticles is inversely proportional to dislocation density. The dislocation density was calculated using Williamson and Smallman's equation (2). The dislocation density for the synthesized CdS nanoparticles was estimated to be $0.4989 \times 10^{15} \mathrm{~m}^{-2}$. Fig. 3 shows variation of crystallite size with dislocation density of the $\mathrm{CdS}$ nanoparticles sintered at $200{ }^{\circ} \mathrm{C}$.

3.1.3. RMS Microstrain (e). X-ray diffraction line broadening profile is mainly caused by non-ideal optics of the instrument and microstructure imperfections in the crystals. The micro structural line broadening can be subdivided 
CdS nanoparticles at 2000C

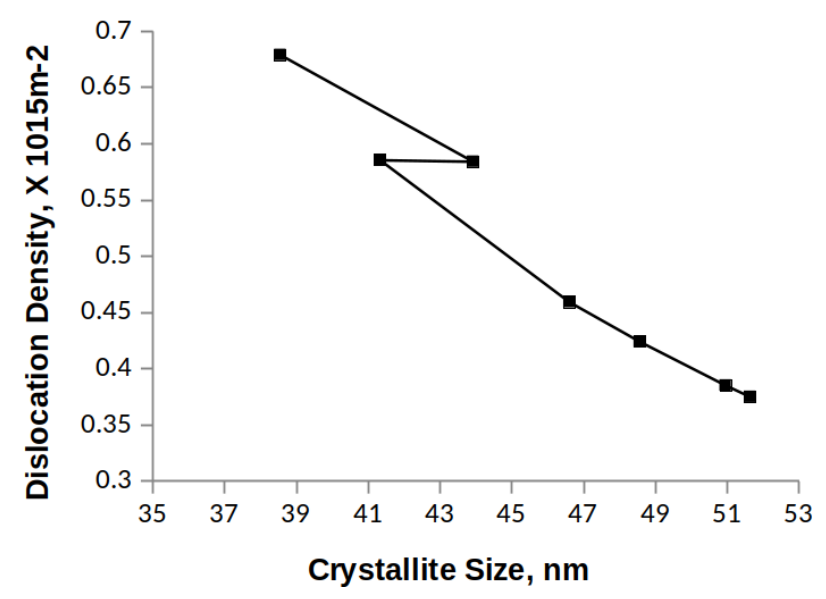

FIG. 3. Variation of dislocation density against crystallite size of CdS nanoparticles

into size broadening and strain broadening [27]. Fig. 4(a) shows the plot of $\beta \cos \theta$ against $2 \sin \theta$ with different deformations at ambient air. The points in the $\mathrm{W}-\mathrm{H}$ are scattered, which is attributed to line broadening is termed anisotropic. $\beta \cos \theta$ is not a monotonic function of $2 \sin \theta$. The RMS microstrain introduced in the sample is possibly due to stacking fault within the crystallites. Since the preparation of nanoparticles is carried out at $90{ }^{\circ} \mathrm{C}$ aerobically, some stress is expected to be introduced, which can result in stacking fault. The microstrain from the Williamson and Hall regression is satisfied because the plots have completely seen distributed in the whole of the graphic. The precise RMS microstrain was taken from the intercept out of linear fit. The value of RMS microstrain is on the lower side compared to that reported 0.4944 by chemical precipitation technique. It was possibly due to large value of average crystallite size $(\sim 50 \mathrm{~nm})$ of the powder samples [28].
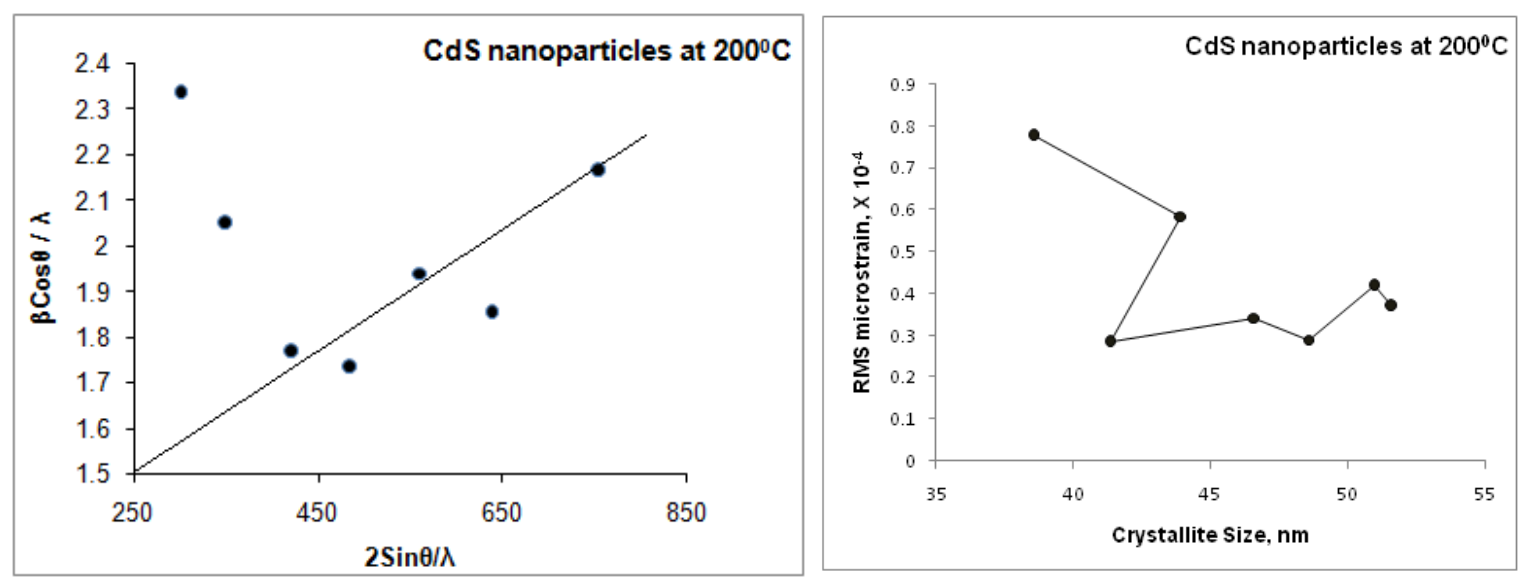

FIG. 4. $\beta \cos \theta$ against $2 \sin \theta$ of CdS nanoparticles (Williamson-Hall plots) (a) and microstrain against crystallite size of CdS nanoparticles (b)

The Williamson-Hall method is one of the simplest methods which clearly differentiates between size-induced and strain-induced peak broadening by considering the peak width as a function of $2 \theta(\mathrm{hkl})$. These estimated values of microstrain indicate a decreasing trend with increases crystallite size with diffraction angle in X-ray diffraction line broadening profile [29] as shown in Fig. 4(b). The calculation of RMS micro strain was done by Williamson-Hall method.

Microstructure parameters of CdS nanoparticles powder sample as shown in Table 2.

3.1.4. Stacking Fault Probability $(\alpha)$. A stacking fault is a planar imperfection that arises from the stacking of one atomic plane out of sequence with another while the lattice on either side of the fault is perfect. The defect is associated with shifting of the planes two theta values of X-ray diffraction profile. It arises when one atomic plane sets out of series than others to start piling up; on the other hand lattice remains surpassing. Due to stacking fault only the 
TABLE 2. Microstructure parameters of cadmium sulfide nanoparticles powder sample

\begin{tabular}{ccccccc}
\hline $\begin{array}{c}\text { Observed } \\
\text { diffraction } \\
\text { angle }(2 \theta) \\
\text { degrees }\end{array}$ & $\begin{array}{c}\text { Calculated } \\
\text { diffraction } \\
\text { angle }(2 \theta) \\
\text { degrees }\end{array}$ & $\begin{array}{c}\mathrm{hkl} \\
(\text { Planes })\end{array}$ & $\begin{array}{c}\text { Crystallite } \\
\text { size, } \\
\mathrm{nm}(D)\end{array}$ & $\begin{array}{c}\text { Dislocation } \\
\text { density, } \mathrm{m}^{2} \\
(\delta) \times 10^{15}\end{array}$ & $\begin{array}{c}\text { Stacking } \\
\text { fault } \\
\text { probability } \\
\alpha\end{array}$ & $\begin{array}{c}\text { RMS } \\
\text { micro } \\
\text { strain } \\
(e) \times 10^{-4}\end{array}$ \\
\hline \hline 26.81 & 28.22 & $\mathrm{C}(111)$ & 38.55 & 0.67901 & 0.47640 & 0.77644 \\
31.32 & 32.51 & $\mathrm{H}(200)$ & 43.92 & 0.58413 & 0.34231 & 0.58530 \\
37.94 & 36.62 & $\mathrm{H}(102)$ & 50.95 & 0.38522 & 0.30966 & 0.41894 \\
43.96 & 44.22 & $\mathrm{C}(220)$ & 51.63 & 0.37514 & 0.05194 & 0.36940 \\
51.28 & 52.10 & $\mathrm{C}(311)$ & 46.60 & 0.45931 & 0.13777 & 0.34185 \\
58.89 & 58.27 & $\mathrm{H}(202)$ & 48.56 & 0.42407 & 0.08855 & 0.29066 \\
71.22 & 72.71 & $\mathrm{C}(331)$ & 41.33 & 0.58542 & 0.16774 & 0.28448 \\
\hline
\end{tabular}

position of peak shows variation from JCPDS for its corresponding sample [30]. The stacking fault probability was calculated using eq. (3). Some of the observed peak broadening can be attributed to fine crystallite size and micro strain effects, anomalous plane (hkl) dependent peak broadening and peak shifts are clearly associated with stacking faults. Whenever the observed value of stacking fault is higher in a particular material then the exact cross slip dislocation can be found. The presence of stacking faults gives rise to a shift in the peak positions of different reflections with respect to ideal positions of a fault free sintered sample [31,32]. The optimized synthesized conditions preferred plane orientation of CdS nanoparticles with larger crystallite size, lower RMS strain, dislocation density and stacking fault probability are obtained. Fig. 5 represent variation of RMS strain, dislocation density, stacking fault probability with diffraction angle of CdS nanoparticles sample at $200{ }^{\circ} \mathrm{C}$.

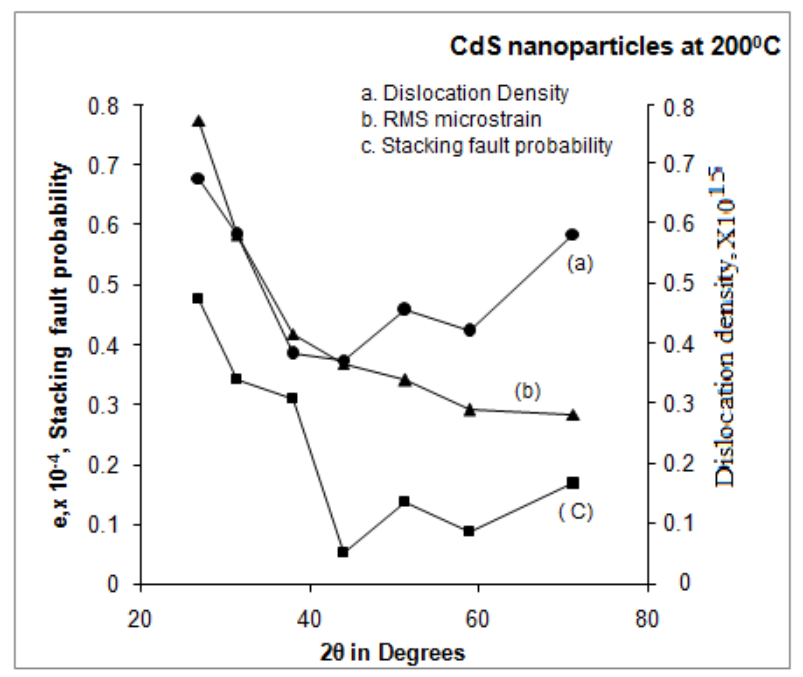

FIG. 5. Variation of RMS strain, dislocation density, stacking fault probability with diffraction angle $(2 \theta)$ of CdS nanoparticles at $200{ }^{\circ} \mathrm{C}$

Figure 6 shows the FESEM image of CdS nanoparticles sintered at $200{ }^{\circ} \mathrm{C}$. The FESEM micrograph clearly illustrates the formation of sub-micrometer crystallites distributed over the surface. Agglomeration of large crystallites also seems to be present in overall regions on the surface of the sample. The average particle size evaluated from FESEM micrograph was found to $74.07 \mathrm{~nm}$.

\subsection{UV-visible spectrophotometer analysis}

The UV-visible optical absorption spectra were recorded at room temperature from a double beam spectrophotometer in the range $200-800 \mathrm{~nm}$. A record spectrophotometer (JASCO UV-VIS-NIR Model No.V-670) was used for these optical measurements of cadmium sulfide nanoparticles. Fig. 7 shows absorption in the near UV region 


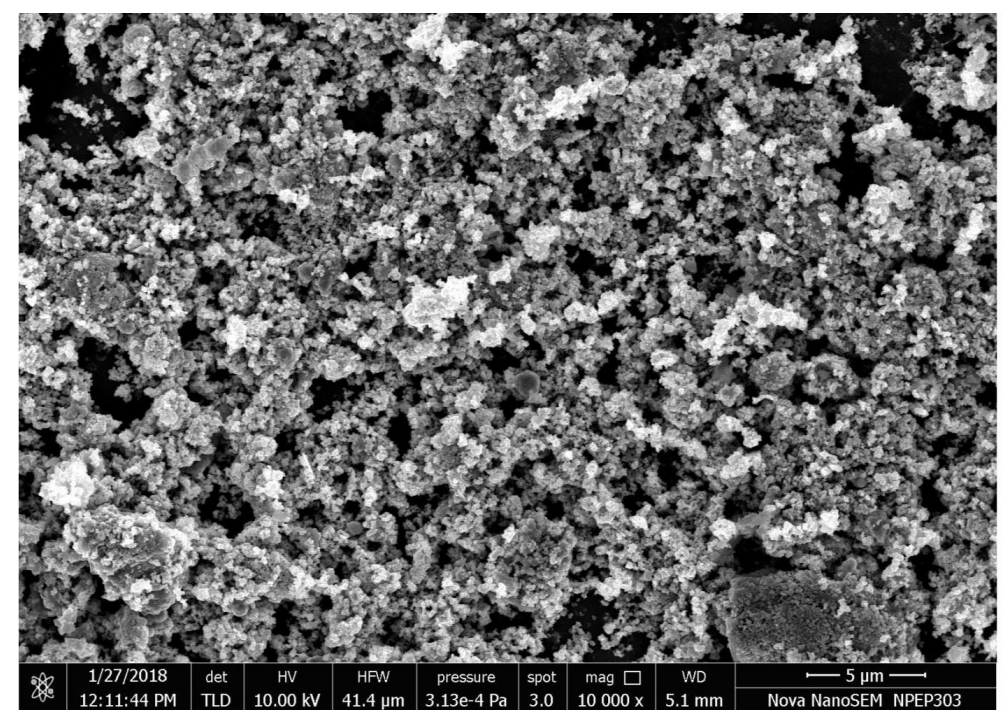

FIG. 6. FESEM image of CdS nanoparticles sintered at $200{ }^{\circ} \mathrm{C}$

arises from electronic transitions associated with in the powder sample. As synthesized CdS nanoparticles sintered at $200{ }^{\circ} \mathrm{C}$, it exhibits a strong absorption band at wavelength near $225 \mathrm{~nm}$ with the absorption edge at about $359 \mathrm{~nm}$.

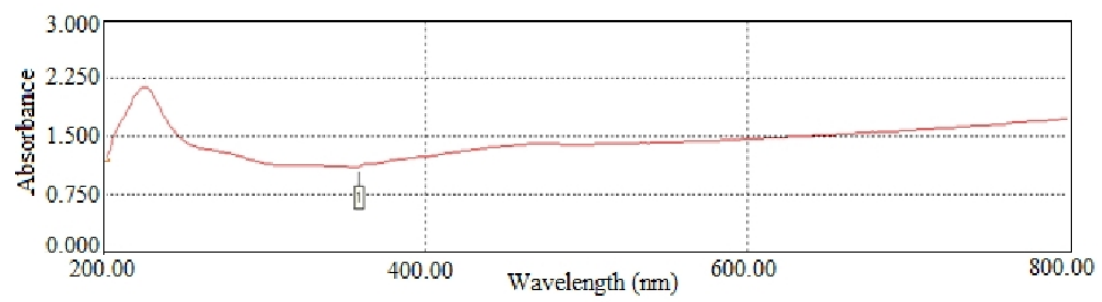

FIG. 7. Optical absorption spectra of CdS nanoparticles sintered at $200{ }^{\circ} \mathrm{C}$

The UV-absorption ability of cadmium sulfide is related with band gap energy. The optical band gap energy was calculated from the dependence of the absorption coefficient on the photon energy using the Tauc relation $(\alpha h \vartheta)=$ $A\left(h \vartheta-E_{g}\right)^{n}$, where $A$ is Tauc's constant, which is a characteristic parameter independent the photon energy, $E_{g}$ is the band gap of the material. The exponent $n$ depends on the type of transition, for that, it takes values for Direct $(n=1 / 2)$, indirect $(n=2)$, direct forbidden transition $(n=3 / 2)$ and forbidden indirect transition $(n=3)$. As a semiconductor, cadmium sulfide has direct allowed transitions, accordingly $n=1 / 2$ is chosen [33]. The band gap energy fallowed direct transition of CdS nanoparticles sintered at $200{ }^{\circ} \mathrm{C}$ was found to be $3.45 \mathrm{eV}$ and it was compared with the bulk cadmium sulfide $E_{g}=2.42 \mathrm{eV}$. It indicates the absorption position depends on the morphologies and crystallite size of CdS. Also, the crystallite size is directly related to the absorption wavelength, As a result, the band gap of the CdS nanoparticles increases, causing a blue-shift in the UV-vis absorption spectra. The band gap energy of CdS nanoparticles has been reported with $E_{g}=3.46 \mathrm{eV}$ [34].

The refractive index of the cadmium sulfide powder sample was calculated using the Herve-Vandamme formula:

$$
n=\left[1+\left(\frac{P}{E_{g}+Q}\right)^{2}\right]^{1 / 2},
$$

where $P=13 \cdot 6 \mathrm{eV}$ and $Q=3 \cdot 4 \mathrm{eV}$ is standard constant values. The refractive index gives information about vacancies present in the $\mathrm{CdS}$ nanoparticles and defines the measurement of density that is, a decrease in the refractive index means a decrease in the material density in the CdS sample. The refractive index of the CdS nanoparticles was found to be 2.22 .

\subsection{FT-IR spectrophotometer analysis}

The infrared spectrum of synthesized cadmium sulfide nanoparticles as in the range of wave number $400-$ $4000 \mathrm{~cm}^{-1}$, which identifies the functional groups and chemical bond in the synthesized compound. The infrared 
spectra of cadmium sulfide nanoparticles are represented in Fig. 8. The large broad band at $3504 \mathrm{~cm}^{-1}$ is ascribed to the O-H stretching of the adsorbed moisture on the cadmium sulfide surface [35]. The bands appearing at 2970 and $2160 \mathrm{~cm}^{-1}$ correspond to $\mathrm{C}-\mathrm{H}$ stretching and bending vibrations. The absorption is sharp and strong peak around $1620 \mathrm{~cm}^{-1}$ is assigned to the symmetric bending vibration of the water molecules [36].

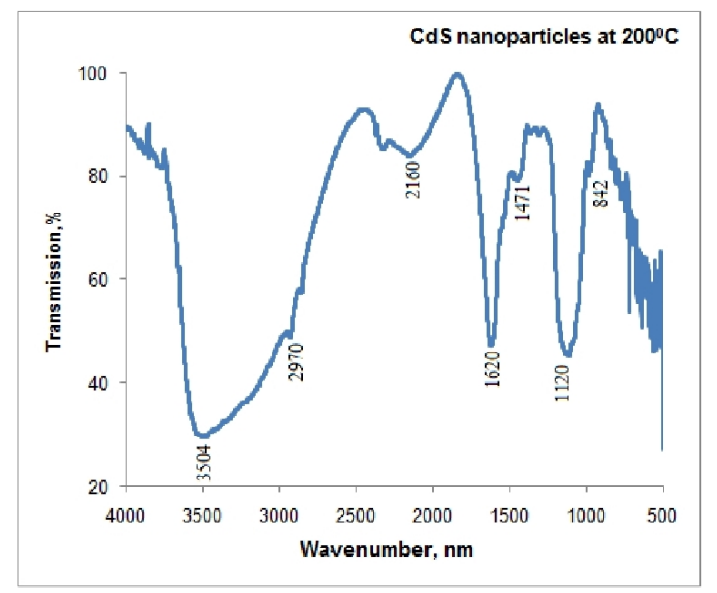

FIG. 8. FTIR of CdS nanoparticles sintered at $200^{\circ} \mathrm{C}$

The band at $1471 \mathrm{~cm}^{-1}$ is assigned to $\mathrm{H}-\mathrm{O}-\mathrm{H}$ characteristics. The Peak at $1125 \mathrm{~cm}^{-1}$ assigned to $\mathrm{C}-\mathrm{O}$ stretching vibration. This band arises from $\mathrm{C}-\mathrm{O}$ linkage stretching and $\mathrm{C}-\mathrm{O}-\mathrm{H}$ bending vibrations [37]. The bands located at around $750 \mathrm{~cm}^{-1}$ have been attributed to the $\mathrm{CO}_{2}$ asymmetric stretching vibration. The strong absorption band located at $670-470 \mathrm{~cm}^{-1}$ was assigned to the $\mathrm{Cd}-\mathrm{S}$ stretching vibration mode, which confirms the formation of cadmium sulfide [38]. These observations convincingly support template role in thioglycerol in the control of the size of CdS particles. The IR study confirms that the $-\mathrm{C}-\mathrm{O}$ and $-\mathrm{OH}$ groups of thioglycerol can readily bind with $\mathrm{CdS}$ nanoparticles [39].

\section{Conclusion}

Large scale CdS nanoparticles were synthesized by a low cost simple chemical route. The XRD results showed that there was a transformation from a cubic to a hexagonal crystalline phase. The observed d-spacing values were found to be in good agreement with the JCPDS data for cubic and hexagonal cadmium sulfide. This clearly indicated that the prepared material is $\mathrm{CdS}$ with cubic and hexagonal structure. The $\mathrm{W}-\mathrm{H}$ plots showed the size and nature of the strain incorporated in peak broadening of $\mathrm{X}$ ray diffraction peaks. The optimized synthetic conditions to CdS nanoparticles with larger crystallite size, lower RMS strain, dislocation density and stacking fault probability were obtained. The refractive index of the CdS nanoparticles was estimated to 2.22 . The band gap energy fallowed direct transition of $\mathrm{CdS}$ nanoparticles sintered at $200{ }^{\circ} \mathrm{C}$ was found to be $3.45 \mathrm{eV}$. FTIR study confirms that the $-\mathrm{C}-\mathrm{O}$ and $-\mathrm{OH}$ groups of thioglycerol can readily bind with $\mathrm{CdS}$ nanoparticles. The quality and particle size obtained in our $\mathrm{CdS}$ nanoparticles suggest that they are suitable for various applications, such as the detection and treatment of cancer and other diseases and for air and water purification.

\section{Acknowledgements}

The author thanks the management authorities of M. G. Vidyamandir's Panchavati Nasik for providing all the required Laboratory and infrastructural facilities for doing this work.

\section{References}

[1] Cao Y., Pengfei H., Dianzeng J. Phase and shapecontrolled hydrothermal synthesis of CdS nanoparticles and oriented attachment growth of its hierarchical architectures. Applied Surface Science, 2013, 265, P. 771-777.

[2] Kumar V., Suryakarthick R., et al. Effect of precursor concentration on the properties and tuning of conductivity between p-type and n-type of $\mathrm{Cu}_{1-x} \mathrm{Cd}_{x} \mathrm{~S}_{2}$ thin films deposited by single step solution process as a novel material for photovoltaic application. RSC Advances, 2015, $\mathbf{5}$, P. 23015-23021.

[3] Aruna Devi R., Latha Z., et al. Synthesis and Characterization of Cadmium Sulfide Nanoparticles by Chemical Precipitation Method. Journal of Nanoscience and Nanotechnology, 2015, 15, P. 8434-8439.

[4] Singh V., Sharma P., Chauhan P. Synthesis of CdS Nanoparticles with Enhanced Optical Properties. Materials Characterization, 2011, 62, P. 43-52. 
[5] Liu Q., Qi Y., Zheng Y., Song X. Synthesis and enhanced photo catalytic activity of g-C $3 \mathrm{~N}_{4}$ hybridized CdS nanoparticles. Bulletin of Materials Science, 2017, 40, P. 1329-1333.

[6] Shrivastav D., Hrivastaval Malik M. Enhancing efficiency of organic light emitting diodes through doping of cadmium sulphide nanocrystals and Application. International Journal of Nanotechnology and Application, 2014, 4 (4), P. 1-6.

[7] Nassr I., Najm K., et al. Highly selective CdS: Ag heterojunction for photodetector applications. AIP Conference Proceedings, 2019, 2123, 020031.

[8] Hetsch F., Zhao N., Kershaw S., Rogach A. Quantum dot field effect transistors. Material today, 2013 , 16 (9), P. $312-325$.

[9] Lee H., Issam A., et al. Synthesis and Characterizations of Bare CdS Nanocrystals Using Chemical Precipitation Method for Photoluminescence Application. Journal of Nanomaterials, 2009, 914501.

[10] Mahsa A., Naader A. Highly photosensitive near infrared photodetector based on polypyrrole nanoparticle incorporated with CdS quantum dots. Materials Science in Semiconductor Processing, 2020, 111 (1), 104964.

[11] Wilson D., Shepherd L. Chemical and biological sensors for environmental monitoring. IEEE International Symposium on Circuits and Systems, Seattle, WA, 2008, P. 1990-1993.

[12] Liu Z., Wang R., Khan F. Jiang F. Synthesis and characterization of $\mathrm{TiO}_{2}$ nanoparticles. Asian Journal of Chemistry, 2014,26 (3), P. $655-659$.

[13] Kowshik M., Deshmukh N., et al. Microbial Synthesis of Semiconductor CdS Nanoparticles, Their Characterization, and Their Use in the Fabrication of an Ideal Diode. Biotechnology and Bioengineering, 2002, 78 (5), P. 583-588.

[14] Kadam A., Dhabbe R., Kokate M., Garadkar K. Room temperature synthesis of CdS nanoflakes for photocatalytic properties. Journal of Materials Science Materials in Electronics, 2014, 25 (4), P. 1887-1892.

[15] Gaur R., Jeevanandam P. Effect of anions on the morphology of CdS nanoparticles prepared via thermal decomposition of different cadmium thiourea complexes in a solvent and in the solid state. New Journal of Chemistry, 2015, 39 (12), P. $9442-9453$.

[16] Gu Li. Fabrication of 2D and 3D dendritic nano architectures of CdS. Transactions of Nonferrous Metals Society of China, 2008,18 (4), P. 904-907.

[17] Fernando V., José L., Fierro G., Yerga R. From Nanorods to Nanowires of CdS Synthesized by a Solvothermal Method: Influence of the Morphology on the Photoactivity for Hydrogen Evolution from Water. Molecules, 2016, 21 (4), P. 401.

[18] Devi R., Latha M., et al. Synthesis and Characterization of Cadmium Sulfide Nanoparticles by Chemical Precipitation Method. Journal of Nanoscience and Nanotechnology, 2015, 15, P. 8434-8439.

[19] Cullity B. Elements of X-ray diffraction. Addison-Wesley Publishing Co., 1956.

[20] Kumar B., Hymavathia B., Subba Rao T. Investigations on physical properties of nanostructured ZnTe thin films prepared by DC reactive magnetron sputtering. Chalcogen. Lett., 2014, 11 (10), P. 509-517.

[21] Yang J., Zeng J., et al. Formation Process of CdS Nanorods via Solvothermal Route. Chem. Mater., 2000 , 12 (11), P. $3259-3263$.

[22] Bially E., Seoudi R., et al. Preparation, Characterization and Physical Properties of CdS nanoparticles with Different Sizes. Journal of Applied Sciences Research, 2012, 8 (2), P. 676-685.

[23] Sama S., Rayarb S., Selvarajanc P. Effect of annealing and dopants on the physical properties of CdS nanoparticles. Journal of Chemical and Pharmaceutical Research, 2015, 7 (3), P. 957-963.

[24] Veerabhadrayya M., Kumari R. Structural Study of Tin Oxide Nanopowders Prepared by Jaggery Mediated Gel Combustion Method. textitInternational Journal of Advanced Scientific Research and Management, 2019, 4 (7), P. 53-57.

[25] Kumar S., Chawla A., Kumar N., Chandra R. High temperature powder diffraction study of ( $\mathrm{Zn}, \mathrm{Cd}) \mathrm{S}$ and $\mathrm{Zn}_{x} \mathrm{Cd}{ }_{1-x} \mathrm{~S}$ nanopowders. $R S C$ Adv., 2011, 1, P. 1078-1082.

[26] Aruna Devi R., Latha Z., et al. Synthesis and Characterization of Cadmium Sulfide Nanoparticles by Chemical Precipitation Method. Journal of Nanoscience and Nanotechnology, 2015, 15, P. 8434-8439.

[27] Garde A., Borse R. Effect of firing temperature on the composition and micro structural parameters of screen printed $\mathrm{SnO}_{2} \mathrm{Thick}$ film resistors. Sensors and Transducers Journal, 2010, 113 (2), P. 95-106.

[28] Singh V., Chauhan P. Structural and optical characterization of CdS nanoparticles prepared by chemical precipitation method. Journal of Physics and Chemistry of Solids, 2009, 70, P. 1074-1079.

[29] Patra S., Mitra P., Kumar S., Pradhan. Preparation of nano dimensional CdS by chemical dipping technique and their characterization. Materials Research, 2011, 14 (1), P. 17-20.

[30] Warren B. X-Ray Measurement of Stacking Fault Widths in fcc Metals. Journal of Applied Physics, 1961,32 , P. 2428.

[31] Frank W., Francis G., Biancaniello S. Stacking faults and crystallite size in mechanically alloyed Cu-Co. Nano structured materials, 1995, $6(1-4)$, P. 429-432.

[32] Thanikaikarasan S., Mahalingam T., Raja M., Kim T. Characterization of electroplated Fe Se thin films. J. Mater. Sci.: Mater. Electron, 2009, 20, P. 727-734.

[33] Kamble M., Rondiya S., et al. Optical, structural and morphological study of CdS nanoparticles: role of sulfur source. Nanomaterials and Energy, 2020, 9 (1), P. 72-81.

[34] Lavand A.B., Malghe Y.S. Visible light photocatalytic degradation of 4-chlorophenol using C/ZnO/CdS Nanocomposites. Journal of Saudi Chemical Society, 2015, 19 (5), P. 471-578.

[35] Verma A., Chandra P., Srivastava A., Shukla R. Optoelectronic studies of commercially and lab prepared cadmium sulfide chalcogenide. Research \& Reviews. Journal of Material Sciences, 2017, 5 (2), P. 28-34.

[36] Rao G., Babu B., Stella R. Synthesis and characterization of $\mathrm{VO}_{2}^{+}$doped ZnO-CdS composite nanopowder. Journal of Molecular Structure, 2015, 1081, P. 254-259.

[37] Seoudi R., Allehyani S., et al. Preparation, Characterization and Size Control of Chemically Synthesized CdS Nanoparticles Capped with Poly (ethylene glycol). Journal of Electronic Materials, 2015, 44, P. 3367-3374.

[38] Terrazas E.C., Ambrosio R., González M. A simple method for the synthesis of CdS nanoparticles using a novel surfactant. Chalcogenide Letters, 2015, 12 (4), P. 147-153.

[39] Devamani R., Alagar M. Synthesis and characteristics of copper (II) Phosphate nanoparticles. Elixir Nanotechnology, 2013, 61, P. 1691716921. 